\title{
Formation and potential mechanisms of polychlorinated dibenzo-p-dioxins and dibenzofurans on fly ash from a secondary copper smelting process
}

\author{
Mei Wang • Guorui Liu • Xiaoxu Jiang • Ke Xiao • \\ Minghui Zheng
}

Received: 28 August 2014 / Accepted: 22 December 2014 /Published online: 10 January 2015

(C) Springer-Verlag Berlin Heidelberg 2015

\begin{abstract}
Secondary copper smelting $(\mathrm{SeCu})$ is widely considered to be an important source of polychlorinated dibenzo$p$-dioxins and dibenzofurans (PCDDs and PCDFs; $\mathrm{PCDD} / \mathrm{Fs}$ ). Laboratory experiments were performed using $\mathrm{SeCu}$ fly ash as a matrix for thermochemical reactions to investigate the effects of fly ash on the formation of PCDD/Fs and the potential mechanisms. Thermochemical reactions on $\mathrm{SeCu}$ fly ash over a temperature range of $250-450^{\circ} \mathrm{C}$ and reaction times of 10 120 min caused the PCDD/F concentrations in the fly ash to increase significantly. The PCDD/F concentrations formed in the thermal reactions were about 99-139 times higher than the PCDD/F concentrations in the original fly ash, clearly indicating that fly ash promoted the formation of PCDD/Fs. The PCDFs dominated the PCDDs, and the PCDF/PCDD concentration ratio was about 30-40. Octachlorodibenzofuran (OCDF), octachlorodibenzo-p-dioxin, and the heptachlorodibenzofurans were the most dominant homologs that were formed. A comparison of the PCDD/F patterns produced in the thermochemical reactions and the patterns in the original fly ash suggested that the chlorination of less chlorinated PCDFs might be an important pathway in the formation of higher chlorinated furans. The results of this study indicated that $\mathrm{SeCu}$ fly ash has a high PCDD/F formation potential. It is
\end{abstract}

Responsible editor: Constantini Samara

Electronic supplementary material The online version of this article (doi:10.1007/s11356-014-4046-6) contains supplementary material, which is available to authorized users.

M. Wang $\cdot$ G. Liu $(\bowtie) \cdot$ X. Jiang $\cdot$ K. Xiao $\cdot$ M. Zheng $(\bowtie)$

State Key Laboratory of Environmental Chemistry and

Ecotoxicology, Research Center for Eco-Environmental Sciences,

Chinese Academy of Sciences, P.O. Box 2871, Beijing 100085,

China

e-mail: grliu@rcees.ac.cn

e-mail: zhengmh@rcees.ac.cn crucial to have the fly ash filter at low temperature and that fly ash in the cooling system should be minimized.

Keywords PCDD/Fs $\cdot$ Secondary copper smelting $\cdot$ Fly ash . Chlorination $\cdot$ Thermal treatment $\cdot$ Persistent organic pollutants

\section{Introduction}

Polychlorinated dibenzo- $p$-dioxins and dibenzofurans (PCDD/Fs) are ubiquitous persistent organic pollutants. The unintentional formation of $\mathrm{PCDD} / \mathrm{Fs}$ in industrial processes and their subsequent emission are important sources of PCDD/Fs to the environment (Fiedler 2007; Liu et al. 2009; UNEP 2013). Secondary nonferrous smelting processes are primarily used to recover nonferrous metals from scrap metal. Scrap metal usually contains organic materials (such as plastics, paints, and oils) that provide carbon and chlorine, allowing PCDD/Fs to be formed (Aittola et al. 1996). Copper is considered to be one of the most efficient metal catalysts for the formation of PCDD/Fs (Chin et al. 2011; Hagenmaier et al. 1987a), and it has been suggested that secondary copper production is one of the most significant sources of $\mathrm{PCDD} / \mathrm{Fs}$ (Ba et al. 2009).

The release of PCDD/Fs from a metal smelter might cause increased risks to workers in the metallurgical industry $(\mathrm{Hu}$ et al. 2013a). The exposure of metallurgical smelting workers to $\mathrm{PCDD} / \mathrm{Fs}$ has been assessed in several studies (Abballe et al. 2013; Hu et al. 2013a; Lee et al. 2009; Shih et al. 2008). Riss et al. analyzed the soil and food (livestock and milk) samples around a copper reclamation plant and found that the milk samples showed a significant increase in PCDD/ 
F levels compared to control samples (Riss et al. 1990). In one study, 10 ambient air samples were collected around electric arc furnaces, secondary copper smelters, and secondary aluminum smelters and analyzed for PCDD/Fs, and the highest $\mathrm{PCDD} / \mathrm{F}$ concentrations were found in air samples collected near copper smelters (Lee et al. 2009). Hu et al. found that workers in some secondary copper smelting $(\mathrm{SeCu})$ plants had daily inhaled PCDD/F doses higher than the tolerable daily intake recommended by the World Health Organization ( $\mathrm{Hu}$ et al. 2013a). These results indicate that the release of PCDD/ Fs from $\mathrm{SeCu}$ plants might pose serious risks to the ambient environment and to human health.

It has been shown that the concentrations of $\mathrm{PCDD} / \mathrm{F}$ emitted from secondary copper smelters were lower than those emitted from the Waelz plants and were higher than those emitted from other metal smelting processes and from waste incinerators (Chi et al. 2008; Nie et al. 2011; Zou et al. 2012). Ba et al. analyzed 30 stack gas and 20 fly ash samples from secondary nonferrous metal smelting plants in China and found that the $\mathrm{SeCu}$ plants had the highest $\mathrm{PCDD} / \mathrm{F}$ toxic equivalency emission factors $(\mathrm{Ba}$ et al. 2009). Similar results have been found in other regions and countries (G Wielgosinski et al. 2011; Yu et al. 2006). These results indicate that $\mathrm{SeCu}$ is an important source of PCDD/Fs. The formation of $\mathrm{PCDD} / \mathrm{Fs}$ during $\mathrm{SeCu}$ processes, and the mechanisms involved, need to be understood so that techniques for controlling PCDD/ $\mathrm{F}$ emissions can be developed.

The formation of PCDD/Fs has been studied in many laboratory simulations with the aim of identifying the characteristics of PCDD/F formation processes and the mechanisms that are potentially involved (Lasagni et al. 2013). However, most of these studies have been focused on municipal waste incineration (MWI) processes (Hagenmaier et al. 1987b; Hajizadeh et al. 2011; Hatanaka et al. 2000; Hung et al. 2013; Weber et al. 2002). For example, Dickson et al. used MWI fly ash and synthetic mixtures containing silica gel and pulverized activated charcoal as matrices in simulation experiments to investigate the thermal formation of PCDD/Fs during MWI processes (Dickson et al. 1992; Karasek and Dickson 1987). Weber et al. studied the de novo synthesis of PCDD/Fs from polycyclic aromatic hydrocarbons on a model MWI fly ash (Weber et al. 2001a). However, no simulation studies have yet been performed to investigate $\mathrm{PCDD} / \mathrm{F}$ formation during $\mathrm{SeCu}$ processes. The chemical compositions and properties of $\mathrm{SeCu}$ fly ash and MWI fly ash are very different, so very different types of thermochemical reactions that could lead to the formation of PCDD/Fs may occur during the $\mathrm{SeCu}$ and MWI processes (Cobo et al. 2009; Gidarakos et al. 2009). The mechanisms that have been found for the formation of PCDD/Fs during MWI processes might not, therefore, perfectly explain the formation of $\mathrm{PCDD} / \mathrm{Fs}$ during $\mathrm{SeCu}$ processes. Therefore, it is important to study the formation of $\mathrm{PCDD} / \mathrm{Fs}$ during $\mathrm{SeCu}$ processes and the mechanisms that are potentially involved, with the aim of developing techniques for preventing the formation and release of $\mathrm{PCDD} / \mathrm{Fs}$ from $\mathrm{SeCu}$ processes.

Fly ash is widely recognized as an important matrix on which the formation of $\mathrm{PCDD} / \mathrm{Fs}$ is promoted during industrial thermal processes (Cobo et al. 2009; Kawamoto 2009). A series of laboratory experiments were performed using $\mathrm{SeCu}$ fly ash as a thermochemical reaction matrix in the study presented here. The aims of the study were to quantify the $\mathrm{PCDD} / \mathrm{Fs}$ formed when $\mathrm{SeCu}$ fly ash was thermally treated and to clarify the characteristics of the PCDD/Fs formed and the mechanisms that were potentially involved. The study was firstly conducted to improve the basic understanding of the formation of $\mathrm{PCDD} / \mathrm{Fs}$ during $\mathrm{SeCu}$ processes and to provide information for improving knowledge to develop techniques and strategies for controlling PCDD/F emissions from $\mathrm{SeCu}$ plants.

\section{Materials and methods}

Basic information on the fly ash sample

In a previous study, we investigated the amounts of $\mathrm{PCDD} / \mathrm{Fs}$ emitted from secondary copper metallurgy plants in China (Ba et al. 2009; Hu et al. 2013b; Nie et al. 2012), and we found large variations in the $\mathrm{PCDD} / \mathrm{F}$ concentrations that were emitted, the highest concentration being about 1000 times higher than the lowest concentration (Hu et al. 2013b). The composition of the raw materials used in a plant was found to be one of the key factors influencing the amount of PCDD/Fs emitted. The highest PCDD/F concentration was found to be emitted from a smelting plant that used only copper scrap as a raw material (Hu et al. 2013b; Nie et al. 2012). In the study presented here, a plant that used only copper scrap as a raw material was selected as an example of an extreme case for which to determine the characteristics of the PCDD/Fs formed during $\mathrm{SeCu}$ processes and the mechanisms that are potentially involved in forming the PCDD/Fs. The selected plant uses a reverberator to smelt copper scrap and produces $110 \mathrm{t}$ of copper per furnace. The raw materials are melted using heavy oil as a fuel, and fine coal is used as the reductant. A fly ash sample was collected from the bag filters in the plant.

\section{Experimental apparatus}

Each of the experimental runs (shown in Supplementary Table S1) was performed in a temperature-controlled tube furnace reactor. A schematic diagram of the apparatus is shown in Fig. 1. Air was passed through the tube furnace at

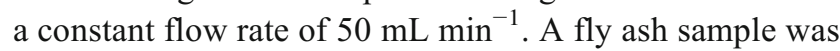


Fig. 1 Tube furnace apparatus used for the thermochemical reaction experiments

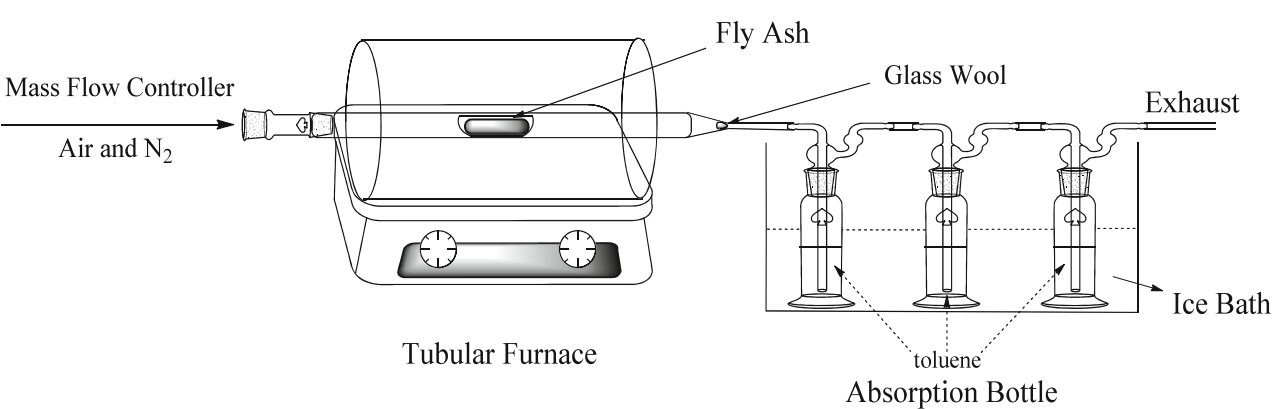

placed in a porcelain boat, which was placed in the furnace, and the furnace was heated to the set temperature (between 250 and $450{ }^{\circ} \mathrm{C}$ ) for between 10 and $120 \mathrm{~min}$. The furnace temperature was increased at $10{ }^{\circ} \mathrm{C} \min ^{-1}$ until the set temperature was reached. The gases produced were trapped in three toluene-filled absorption bottles, which were held in an ice bath, connected (in series) to the end of the reaction tube. After each experimental run, the reactor (a quartz tube) and all of the fittings and connecting tubes were rinsed with toluene to recover any products that had been deposited on the surfaces. The toluene used for rinsing (cleaning solution) was combined with the toluene from the absorption bottles (absorption solutions 1, 2, and $3)$. The solid residues and the toluene were stored at around $4{ }^{\circ} \mathrm{C}$ until they were analyzed.

\section{Extraction, cleanup, and analysis}

The PCDD/F concentrations in the solid residues and gas samples were determined by isotopic dilution highresolution gas chromatography and high-resolution mass spectrometry (HRGC/HRMS). The sample extraction, cleanup, and instrumental analysis procedures have been described in detail elsewhere (Ba et al. 2009). Briefly, a solid residue sample from a thermochemical reaction experiment was spiked with known amounts of the ${ }^{13} \mathrm{C}_{12}$-labeled PCDD/F internal standards. The solid residue was then digested in $1 \mathrm{M} \mathrm{HCl}$, filtered, rinsed with distilled water, dried, and Soxhlet-extracted with $250 \mathrm{~mL}$ of toluene for about $24 \mathrm{~h}$. Each gas phase sample was spiked with known amounts of the ${ }^{13} \mathrm{C}_{12}$-labeled PCDD/F internal standards. Each extract was evaporated to a small volume using a rotary evaporator and then subjected to a series of cleanup steps, including a column containing silica gel treated with $44 \%$ (by weight) sulfuric acid, a multilayer silica gel column, and a basic alumina column. After the cleanup steps had been completed, the fraction containing the $\mathrm{PCDD} / \mathrm{Fs}$ was evaporated to a volume of about $20 \mu \mathrm{L}$ using a rotary evaporator and then a gentle stream of $\mathrm{N}_{2}$, and then ${ }^{13} \mathrm{C}_{12}$-labeled PCDD/F injection standards were added so that the recoveries of the internal standards could be calculated.
HRGC/HRMS measurements were carried out by an Agilent 6890 gas chromatograph coupled to an AutoSpec Ultima mass spectrometer (Waters). A DB-5 MS fused silica capillary column (60 m long, $0.25 \mathrm{~mm}$ i.d., $0.25-\mu \mathrm{m}$ film thickness) was used. Helium was used as the carrier gas. The HRMS was equipped with an electron impact (EI+) source. The analyzer mode of the selected ion monitoring (SIM) was used with a resolving power of over 10,000. The electron energy and source temperature were specified at $35 \mathrm{eV}$ and $270{ }^{\circ} \mathrm{C}$, respectively.

\section{Quality control and assurance}

Before the thermochemical reaction experiments were carried out, a series of pre-experiments were performed to assess the absorption efficiencies and experimental repeatabilities. The $\mathrm{PCDD} / \mathrm{Fs}$ produced during the thermochemical reaction experiments were mainly found in the cleaning solution and the absorption solution 1 (91-98\%), and small amounts of $\mathrm{PCDD} /$ Fs were found in the absorption 2 (2-9\%), as is shown in Supplementary Table S3. Reaction time ranged from 10 to $120 \mathrm{~min}$ in this study. The experimental repeatabilities at different thermochemical reaction times $(10,30$, and $120 \mathrm{~min})$ were assessed. The relative standard deviations (RSDs) in duplicate runs ranged from 4 to $17 \%$ for $10 \mathrm{~min}$ of thermochemical reactions, and from 6 to $18 \%$ for $120 \mathrm{~min}$ of reactions. The RSD were in the range of $1-21 \%$ at $30 \mathrm{~min}$ of thermochemical reactions in the triplicate runs. The detailed results with $30 \mathrm{~min}$ of thermal reactions as an example are shown in the Supplementary Table S4. The recoveries of the ${ }^{13} \mathrm{C}_{12}$-labeled PCDD/Fs were $59-110 \%$. Toxic equivalents (TEQs) were calculated using the international toxicity equivalency factor (I-TEF) and World Health Organization toxicity equivalency factor (shown in Supplementary Table S2). Laboratory blanks were included with each batch of samples analyzed. Each experimental blank was produced by performing a thermochemical reaction experiment using an empty porcelain boat. The octachlorodibenzo- $p$-dioxin (OCDD) and octachlorodibenzofuran (OCDF) concentrations in the experimental blanks were $0.02-0.13 \%$ and $0.01-0.05 \%$, respectively, of the concentrations found in the samples. Therefore, the PCDD/F concentrations in the samples were not corrected for the blank concentrations. 


\section{Results and discussion}

$\mathrm{PCDD} / \mathrm{F}$ concentrations and their dependence on temperature and time

The PCDD/F concentrations in the solid residues and the gas phase samples were determined. The PCDD/Fs produced during the thermal reactions were mainly found in the gas phase (86-99\%), and small proportions of the PCDD/Fs were found in the solid residues (between $<1$ and $14 \%$ ), as is shown in Supplementary Fig. S1. Therefore, the PCDD/F concentrations in the gas phase are mainly discussed here.

The amounts of the PCDD/Fs formed when the fly ash was heated to 250,350 , and $450{ }^{\circ} \mathrm{C}$ for $30 \mathrm{~min}$ were determined to assess the dependence of the amount of PCDD/Fs formed on the temperature. The PCDD/F concentrations that were produced during the thermal reactions are presented in Fig. 2. The total PCDD and total PCDF concentrations in the untreated fly ash were 0.4 and $1.7 \mu \mathrm{g} / \mathrm{g}$, respectively. It can be seen from Fig. 2 that higher concentrations of the PCDFs than the PCDDs were found in the samples produced by the thermochemical reactions. The total PCDD concentration produced by the fly ash during a 30-min thermal reaction increased from $5.1 \mu \mathrm{g} / \mathrm{g}$ at $250{ }^{\circ} \mathrm{C}$ to $7.7 \mu \mathrm{g} / \mathrm{g}$ at $350{ }^{\circ} \mathrm{C}$ and to $8.0 \mu \mathrm{g} / \mathrm{g}$ at $450{ }^{\circ} \mathrm{C}$. The total PCDF concentration produced during a $30-$ min thermal reaction increased from $204 \mu \mathrm{g} / \mathrm{g}$ at $250{ }^{\circ} \mathrm{C}$ to $255 \mu \mathrm{g} / \mathrm{g}$ at $350{ }^{\circ} \mathrm{C}$ and to $246 \mu \mathrm{g} / \mathrm{g}$ at $450{ }^{\circ} \mathrm{C}$. The variations in the concentrations of PCDD produced after 30-min thermal reactions at temperatures between 250 and $450{ }^{\circ} \mathrm{C}$ were not obvious. In contrast, apparent increases in PCDF concentrations were found after 30 -min thermal reactions at temperatures between 250 and $350^{\circ} \mathrm{C}$. The total PCDF concentrations found after the thermal treatment were approximately 30-40 times higher than the total PCDD concentrations found after the thermal treatment. Figure 2 shows that the highest total

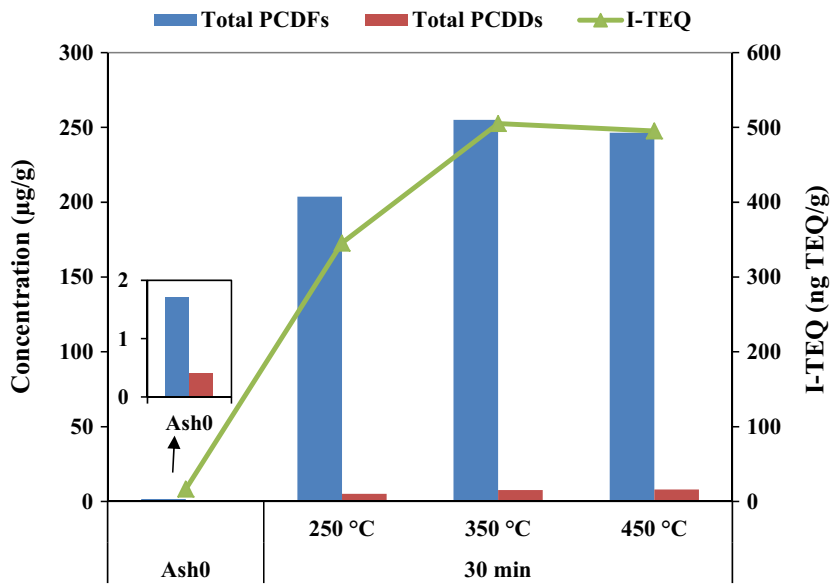

Fig. 2 Concentrations and TEQs of polychlorinated dibenzo- $p$-dioxin (PCDD) and polychlorinated dibenzofuran (PCDF) in the original fly ash and the samples produced by treating the fly ash for $30 \mathrm{~min}$ at 250 , 350 , and $450{ }^{\circ} \mathrm{C}(A \operatorname{sh} 0=$ original fly ash $)$
PCDF concentration was found when the fly ash was treated for $30 \mathrm{~min}$ at $350{ }^{\circ} \mathrm{C}$, and this was about 150 times higher than the concentration in the original fly ash.

The concentration profiles of 2,3,7,8-substituted PCDD/F congeners produced during the thermal reactions are presented in Fig. 3. Thermal treatment of the original fly ash resulted in significant formations of 2,3,7,8-substituted PCDD/Fs. The concentrations of 2,3,7,8-substituted PCDD/F (203.5$252.7 \mu \mathrm{g} / \mathrm{g}$ ) found after the thermal reactions were about 110-137 times higher than those in the original fly ash $(1.85 \mu \mathrm{g} / \mathrm{g})$. TEQ values (I-TEQ and WHO-TEQ) of PCDD/ $\mathrm{F}$ in the thermal reactions and original fly ash are shown in Supplementary Table S7. It can be seen from Fig. 2 that the ITEQs of PCDD/F increased significantly after the thermal treatment of the original fly ash. I-TEQs of PCDD/F were in the range of 345.5-505.2 $\mathrm{ng} \mathrm{TEQ} / \mathrm{g}$ after 30-min thermal reactions at temperatures between 250 and $450{ }^{\circ} \mathrm{C}$. The maximum I-TEQ of PCDD/F (505.2 ng TEQ/g) was found when the fly ash was treated at $350{ }^{\circ} \mathrm{C}$ for $30 \mathrm{~min}$. The I-TEQs of $\mathrm{PCDD} / \mathrm{F}$ in the thermal reactions at $250-450{ }^{\circ} \mathrm{C}$ after $30 \mathrm{~min}$ were approximately 20-30 times higher than that in the original fly ash.

The formation of PCDD/Fs has been investigated in many laboratory simulation studies, and the reaction times used in those studies ranged from a few minutes to hours (Lasagni et al. 2013; Lenoir et al. 2012; Liu et al. 2011). The raw materials are added to the furnace in several batches during a real $\mathrm{SeCu}$ process, so the feeding and fusion stage will take several hours (Hu et al. 2013b). Taking into consideration the simulation studies that have been performed previously and the operating conditions used in real $\mathrm{SeCu}$ processes, we investigated the formation of PCDD/Fs in the fly ash heated to $350{ }^{\circ} \mathrm{C}$ for $10,30,60$, and $120 \mathrm{~min}$, to assess the dependence of the formation of PCDD/Fs on time. The PCDD/F concentrations produced during the thermal reactions are presented in Fig. 4. It can be seen from Fig. 4 that the total PCDD/F concentrations produced during the thermochemical reactions at $350{ }^{\circ} \mathrm{C}$ for between 10 and $120 \mathrm{~min}$ were far higher than the concentration in the original fly ash. The total PCDD and total PCDF concentrations after the fly ash had been heated to $350{ }^{\circ} \mathrm{C}$ for $10 \mathrm{~min}$ were 5.6 and $254 \mu \mathrm{g} / \mathrm{g}$, respectively. A significant amount of PCDFs had been formed in $10 \mathrm{~min}$ of treatment. The total PCDD had not increased significantly after $10 \mathrm{~min}$ of thermal treatment. It can be seen from Fig. 4 that the ITEQs of PCDD/F produced during the thermal reactions at $350{ }^{\circ} \mathrm{C}$ between 10 and $120 \mathrm{~min}$ were far higher than that in the original fly ash. I-TEQs of PCDD/F were in the range of 448.0-507.5 $\mathrm{ng} \mathrm{TEQ} / \mathrm{g}$ after 10-120-min thermal treatment at $350{ }^{\circ} \mathrm{C}$. The maximum I-TEQ of PCDD/F (507.5 ng TEQ/g) was found when the fly ash was treated for $120 \mathrm{~min}$ at $350{ }^{\circ} \mathrm{C}$, and was approximately 31 times higher than that found in the original fly ash. Several factors that strongly affect the formation of PCDD/Fs were characterized. Copper and zinc are 
Fig. 3 Concentration profiles of 17 toxic 2,3,7,8-substituted

$\mathrm{PCDD} / \mathrm{F}$ congeners in the original fly ash and in the samples produced when the fly ash was treated for $30 \mathrm{~min}$ at 250,350, and $450{ }^{\circ} \mathrm{C}(A \operatorname{sh} 0=$ original fly ash $)$

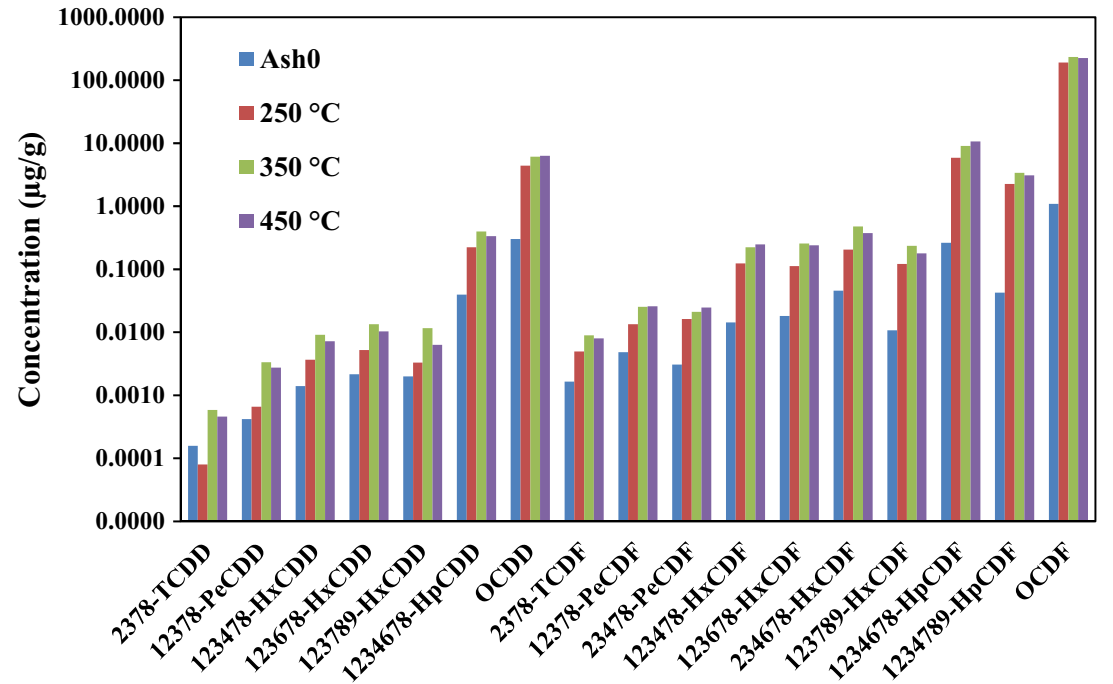

widely recognized as being efficient catalysts for the formation of PCDD/Fs (Chang and Chung 1998; Conesa et al. 2011; Fujimori et al. 2011; Gidarakos et al. 2009; Hagenmaier et al. 1987b). A higher copper concentration was found in the $\mathrm{SeCu}$ fly ash used in this study $(260 \mathrm{mg} / \mathrm{g})$ than has been found in MWI fly ash (0.3-4.6 mg/g) (Cains et al. 1997). The zinc concentration in the fly ash used in this study was $166 \mathrm{mg} / \mathrm{g}$, which was also higher than has been found in MWI fly ash (0.7-30.6 mg/g) (Hoffman et al. 1990). The presence of chlorine is also an important factor that affects the formation of PCDD/Fs (Wikström et al. 2003). The fly ash used in this study had a chlorine content of $8.8 \%$. Detailed information on this analysis is provided in the supplementary materials (Supplementary Tables S5 and S6). The presence of copper, zinc, and chlorine can strongly promote the formation of $\mathrm{PCDD} / \mathrm{Fs}$ and result in significant amounts

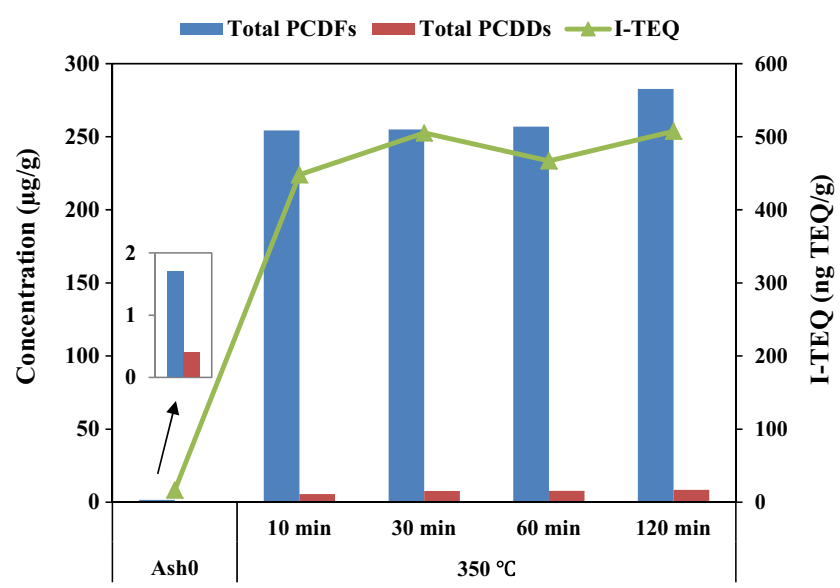

Fig. 4 Concentrations and TEQs of polychlorinated dibenzo- $p$-dioxin (PCDD) and polychlorinated dibenzofuran (PCDF) in the original fly ash and the samples produced by treating the fly ash at $350{ }^{\circ} \mathrm{C}$ for 10 , 30,60 , and $120 \min (A s h 0=$ original fly ash $)$ of PCDD/F being produced in a short time. In this study, the total PCDD/F concentration produced after only $10 \mathrm{~min}$ of treatment at $350{ }^{\circ} \mathrm{C}$ was $260 \mu \mathrm{g} / \mathrm{g}$, which was 124 times higher than the concentration in the original fly ash.

The formation of PCDD/Fs in the fly ash at $350{ }^{\circ} \mathrm{C}$ for 30 min under a $\mathrm{N}_{2}$ rather than air atmosphere was also investigated. The total PCDD and total PCDF concentrations found after $30 \mathrm{~min}$ of treatment at $350{ }^{\circ} \mathrm{C}$ were 0.6 and $15 \mu \mathrm{g} / \mathrm{g}$, respectively, under $\mathrm{N}_{2}$, and 7.7 and $255 \mu \mathrm{g} / \mathrm{g}$, respectively, under air. The total PCDD and total PCDF concentrations produced were about 13 and 17 times higher, respectively, under air than under $\mathrm{N}_{2}$. These results show that heating the fly ash under $\mathrm{N}_{2}$ led to much lower PCDD/F concentrations being produced than were produced when the fly ash was heated under air. This suggests that oxygen is an important factor that influences PCDD/F formation during $\mathrm{SeCu}$ processes. This is in agreement with the previous studies (Hagenmaier et al. 1987b).

The amounts of $\mathrm{PCDD} / \mathrm{F}$ that were produced during the thermal reactions were 99-139 times higher than the amount that was in the original fly ash (Supplementary Table S7). Meanwhile, the I-TEQs of PCDD/F after the thermochemical reactions were approximately 21-31 times higher than that in the original fly ash. To save energy and improve the economics of the process, fly ash is normally recycled by adding it to the raw material or simply thermally treating it in the smelting system in real $\mathrm{SeCu}$ smelting processes, and this ensures that the precious metal present in the fly ash is recycled into the smelted product (Hu et al. 2013b). The results of our study suggest that fly ash needs to be disposed of safely rather than simply being recycled into the raw materials or thermally treated. The fly ash residues that are deposited in the ventilating ducts in metallurgy equipment should be periodically removed to avoid relatively large amounts of $\mathrm{PCDD} / \mathrm{Fs}$ being formed in them. 
PCDD/F homolog profiles and potential formation mechanisms during thermal reactions

The homolog profiles of the PCDD/Fs produced during the thermochemical reaction experiments were compared with the profiles in the original fly ash to attempt to gain an understanding of the $\mathrm{PCDD} / \mathrm{F}$ formation pathways during the treatments. The homolog fractions in PCDD and PCDF produced during the thermal reactions and in the original fly ash are shown in Fig. 5a, b. The homolog patterns of the PCDD/Fs produced during the thermochemical reactions and in the original fly ash were clearly dominated by the higher chlorinated homologs. OCDF made a particularly large contribution to the total amount of PCDD/F produced in all of the samples. The PCDD and PCDF homolog fractions increased with increasing number of chlorine substituent. And, OCDD contributed the most to the PCDDs and OCDF contributed the most to the PCDFs, respectively.

The OCDF contribution to the total amount of PCDFs was clearly higher after the thermal reactions than in the original fly ash. However, the tetrachlorinated to heptachlorinated PCDD/F homologs showed the opposite trend. As is shown in Fig. 5, the OCDF contribution rates to the total amount of PCDFs were 93,91 , and $91 \%$ when the fly ash had been treated at 250,350 , and $450{ }^{\circ} \mathrm{C}$ for $30 \mathrm{~min}$, respectively, and were far higher than the OCDF contribution to the total amount of PCDFs in the original fly ash (64.4\%). However, the tetrachlorinated to heptachlorinated PCDF homologs made much smaller contributions to the total amounts of PCDFs in the thermal reactions than in the original fly ash. This indicates that the chlorination of the less chlorinated PCDF homologs might be an important pathway for the production of OCDF. However, the changes in the contributions made by the PCDD homologs to the total amounts of PCDDs did not match the changes in the contributions made by the PCDF homologs to the total amounts of PCDFs, indicating that the PCDDs and PCDFs had different formation mechanisms.

It has been found in previous studies that copper and zinc are effective in promoting the chlorination pathway for forming $\mathrm{PCDD} / \mathrm{Fs}$, and copper and zinc concentrations have been found to positively correlate with $\mathrm{PCDD} / \mathrm{F}$ concentrations in fly ash (Altarawneh et al. 2009; Fujimori et al. 2013; Weber et al. 2001a, b). Stieglitz et al. proposed that surfacebound copper plays a key role in the chlorination reaction and causes the efficient chlorination of carbon substrates, a process that causes the de novo formation of PCDD/Fs (Schwarz and Stieglitz 1992; Stieglitz 1998; Weber et al. 2001a, b). Ryu et al. speculated that chlorine at a high concentration could be converted to $\mathrm{Cl}_{2}$ on a copper catalyst and that a large number
Fig. 5 a Polychlorinated dibenzo-p-dioxin (PCDD) and b polychlorinated dibenzofuran (PCDF) homolog profiles (as contributions to the total PCDD and total PCDF concentrations, respectively) produced during the thermal reactions and in the original fly ash. $(A \operatorname{sh} 0=$ original fly ash; $T e C D D=$ tetrachlorodibenzo- $p$-dioxin; $P e C D D=$ pentachlorodibenzop-dioxin; $H x C D D=$ hexachlorodibenzop-dioxins; $H p C D D=$ heptachlorodibenzo- $p$-dioxin; $O C D D=$ octachlorodibenzop-dioxin; $T e C D F=$ tetrachlorodibenzofuran; $\mathrm{PeCDF}=$

pentachlorodibenzofuran; $H x C D F=$

hexachlorodibenzofuran; $H p C D F=$

heptachlorodibenzofuran; $O C D F=$ octachlorodibenzofuran)

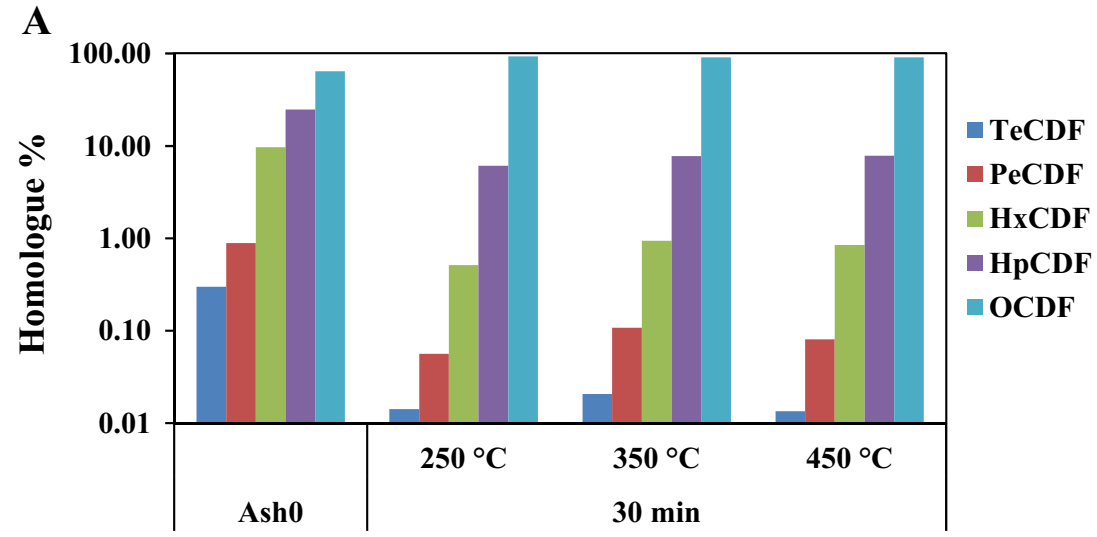

B

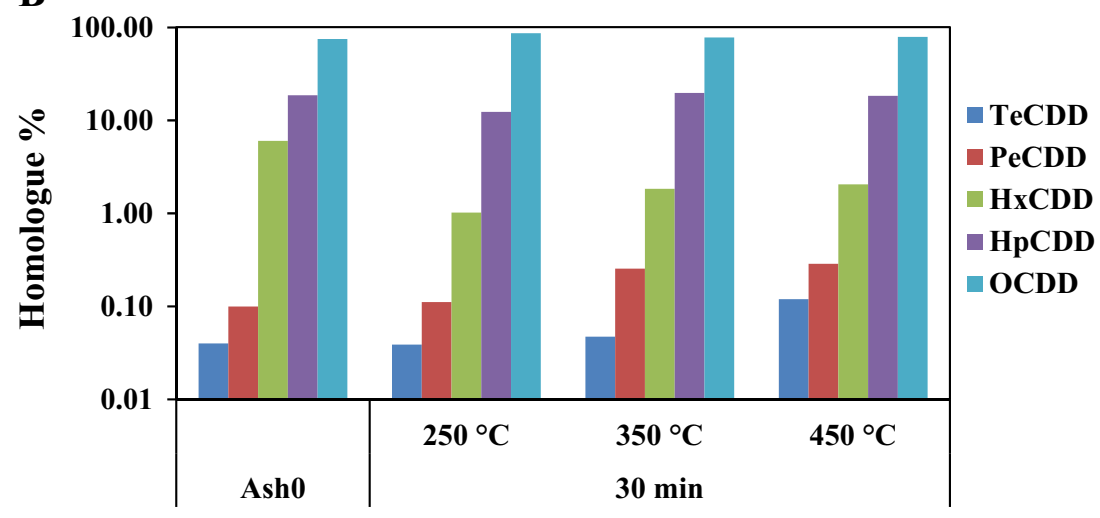


of chlorine radicals will be released (Ryu et al. 2013). The fly ash used in this study contained high concentrations of copper, zinc, and chlorine. Chlorine in the original fly ash might have been converted into chlorine-containing gas during the thermochemical reactions, this process being catalyzed by copper or zinc on the surfaces of the fly ash particles, as suggested by the reactions described by Ryu (Ryu et al. 2013). An absorbent trap containing a solution of sodium carbonate was used to capture the chlorine-containing gas at the outlet of the thermal treatment system in our study, to test the hypothesis that chlorine was involved in the reactions that occurred during the thermal treatments. The chloride ion concentrations in the used sodium carbonate solution were determined by ion chromatography. Detailed information on this analysis is provided in the Supporting Information (Table S8). A high chlorine concentration, equivalent to $9.1 \times 10^{-4} \mathrm{~mol} / \mathrm{g}$ in the original fly ash, was found when the fly ash was treated at $350{ }^{\circ} \mathrm{C}$ for $10 \mathrm{~min}$. This proves that chlorine was produced when the fly ash was heated. The chlorine produced could have been involved in the reactions that produced PCDD/Fs during the thermal treatments.

Wikstrom et al. found an unequivocal relationship between the amount of chlorine added to a system and the PCDD/F yield, with the PCDD/F homolog profile being dominated by the higher chlorinated homologs, especially the octachlorinated and heptachlorinated homologs (Wikström et al. 2003). In a review, Mackie et al. stated that sequential chlorination may occur when an excess of chlorine atoms is present and that an abstraction and displacement process will continue until all of the hydrogen atoms on an aromatic ring have been replaced with chlorine, meaning that the most chlorinated $\mathrm{PCDD} / \mathrm{F}$ homologs will be produced (Altarawneh et al. 2009). This was supported by the results of experiments performed by Eiceman et al (Eiceman and Rghei 1982; Rghei and Eiceman 1985a, b). In our study, the chlorine concentration in the $\mathrm{SeCu}$ fly ash was estimated to be $2.5 \times 10^{-3} \mathrm{~mol} / \mathrm{g}$ from the $8.8 \%$ chlorine content that was determined using energy-dispersive X-ray analysis (Supplementary Table S5). The PCDD/Fs that were formed during the thermal reactions were dominated by the OCDF, heptachlorodibenzofuran (HpCDF), and OCDD homologs (in decreasing contribution order), which together accounted for $98-99 \%$ of the total amount of PCDD/Fs formed. The chlorine content contributed from the OCDF produced when the original fly ash was heated for $30 \mathrm{~min}$ was $3.41 \times 10^{-6} \mathrm{~mol} / \mathrm{g}$ at $250^{\circ} \mathrm{C}, 4.2 \times 10^{-6} \mathrm{~mol} /$ g at $350{ }^{\circ} \mathrm{C}$, and $4.0 \times 10^{-6} \mathrm{~mol} / \mathrm{g}$ at $450^{\circ} \mathrm{C}$, respectively. The chlorine content contributed from the HpCDF produced when the original fly ash was heated for $30 \mathrm{~min}$ was $2.1 \times 10^{-7} \mathrm{~mol} / \mathrm{g}$ at $250{ }^{\circ} \mathrm{C}, 3.4 \times 10^{-7} \mathrm{~mol} / \mathrm{g}$ at $350^{\circ} \mathrm{C}$, and $3.3 \times 10^{-7} \mathrm{~mol} / \mathrm{g}$ at $450{ }^{\circ} \mathrm{C}$, respectively. The chlorine content from the OCDD produced when the original fly ash was heated for 30 min was $8 \times 10^{-8} \mathrm{~mol} / \mathrm{g}$ at $250{ }^{\circ} \mathrm{C}, 1.0 \times 10^{-7} \mathrm{~mol} / \mathrm{g}$ at $350{ }^{\circ} \mathrm{C}$, and $1.1 \times$ $10^{-7} \mathrm{~mol} / \mathrm{g}$ at $450^{\circ} \mathrm{C}$, respectively. The chlorine content contributed from the OCDF, HpCDF, and OCDD produced when the original fly ash was heated for $30 \mathrm{~min}$ at $250-450{ }^{\circ} \mathrm{C}$ was only about $1.5-1.9 \%$ of the chlorine content in the original fly ash. This indicates that far more chlorine was present in the original fly ash than present in the PCDD/Fs that were generated, so there would have been an excess of chlorine when the reactions that formed the $\mathrm{PCDD} / \mathrm{Fs}$ occurred. As mentioned above, the direct chlorination of aromatic compounds, catalyzed by chlorine radicals, can occur when there is an excess of chlorine present, resulting in relatively high concentrations of chlorinated aromatic compounds being formed (Altarawneh et al. 2009). As can be seen from Fig. 5, the tetrachlorinated to heptachlorinated PCDF homolog contributions to the total amounts of PCDD/Fs produced decreased sharply when the fly ash was thermally treated, whereas the OCDF contribution clearly increased. Furthermore, the higher chlorinated PCDFs were the dominant homologs that were produced during the thermochemical reactions. As is shown in Fig. 6, the OCDF, HpCDFs and OCDD concentrations were
Fig. 6 Octachlorodibenzofuran (OCDF),

heptachlorodibenzofuran

(HpCDF), and

octachlorodibenzo- $p$-dioxin (OCDD) concentrations in the original fly ash and in the samples produced when the fly ash was treated for $30 \mathrm{~min}$ at 250,350 , and $450{ }^{\circ} \mathrm{C}(A \operatorname{sh} 0=$ original fly ash $)$

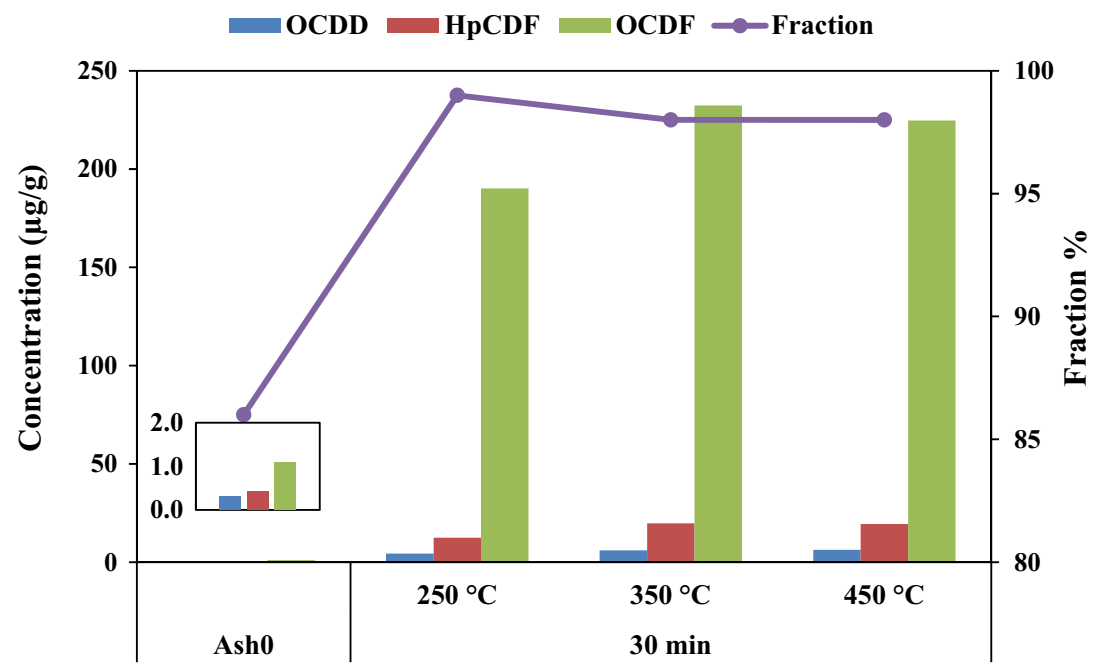


increased significantly by the thermal treatments. The sum of the OCDF, HpCDF, and OCDD concentrations was about 115-143 times higher after the fly ash had been treated at $250-450{ }^{\circ} \mathrm{C}$ for 30 min than those in the original fly ash. It can also be seen from Fig. 6 that the sum of the OCDF, HpCDF, and OCDD concentrations contributed 99,98 , and $98 \%$ of the total amount of $\mathrm{PCDD} / \mathrm{Fs}$ produced when the fly ash was treated at 250, 350, and $450{ }^{\circ} \mathrm{C}$ for $30 \mathrm{~min}$, respectively, that these contributions were far higher than was found in the original fly ash $(86 \%)$. Based on the above analysis, these results of this study indicate that the chlorination of the less chlorinated PCDD/F homologs could be one of the important pathways in the formation of higher chlorinated PCDD/F homologs, and, in particular, OCDF. The oxychlorination and breakdown steps of carbon definitely make great contribution to the formation of higher chlorinated furans (Weber et al. 2001b). The large amounts of PCDF formed in thermal reactions might be formed through multiple pathways including chlorination, de novo synthesis, and so on. The evidence presented here for the importance of the chlorination pathway to the formation of PCDFs might improve our fundamental understanding of the $\mathrm{PCDD} / \mathrm{F}$ formation mechanisms that occur during $\mathrm{SeCu}$ processes and help in the development of practical PCDD/F source control measures.

\section{Conclusions}

Laboratory experiments were performed in which fly ash from a SeCu plant was used as a matrix for thermochemical reactions, to clarify the characteristics of the $\mathrm{PCDD} / \mathrm{Fs}$ formed during $\mathrm{SeCu}$ processes and to identify potential mechanisms for the formation of the PCDD/Fs. Thermal treatment of the fly ash resulted in significant amounts of PCDD/Fs being produced. The highest PCDD/F concentration we found was about 139 times higher than the concentration in the original fly ash, suggesting that fly ash is an important matrix for the formation of $\mathrm{PCDD} / \mathrm{Fs}$ during $\mathrm{SeCu}$ processes. The homolog patterns of the $\mathrm{PCDD} / \mathrm{Fs}$ produced during the thermal reactions were clearly dominated by the fully chlorinated homologs. A comparison of the homolog patterns of the PCDD/Fs produced during the thermochemical reactions with the patterns in the original fly ash suggested that chlorination of the less chlorinated PCDF homologs might be one of important pathway for the formation of higher chlorinated homologs. The results of this study indicated that the $\mathrm{SeCu}$ fly ash has a high PCDD/F formation potential. It is crucial to have the dust filter at low temperature and that dust in the cooling system should be minimized.
Acknowledgments We gratefully acknowledge support from the National Natural Science Foundation of China (21107123; 21321004), the Young Scientists Fund of RCEES (RCEES-QN-20130002F), and Beijing Municipal Science and Technology Commission (Z141100001014001).

\section{References}

Abballe A et al (2013) Occupational exposure to PCDDs, PCDFs, and PCBs of metallurgical workers in some industrial plants of the Brescia area, northern Italy. Chemosphere 90:49-56. doi:10.1016/ j.chemosphere.2012.06.073

Aittola J-P, Paasivirta J, Vattulainen A, Sinkkonen S, Koistinen J, Tarhanen J (1996) Formation of chloroaromatics at a metal reclamation plant and efficiency of stack filter in their removal from emission. Chemosphere 32:99-108. doi:10.1016/0045-6535(95)00236-7

Altarawneh M, Dlugogorski BZ, Kennedy EM, Mackie JC (2009) Mechanisms for formation, chlorination, dechlorination and destruction of polychlorinated dibenzo-p-dioxins and dibenzofurans (PCDD/Fs). Prog Energ Combust 35:245-274. doi:10.1016/j.pecs. 2008.12.001

Ba T, Zheng M, Zhang B, Liu W, Xiao K, Zhang L (2009) Estimation and characterization of $\mathrm{PCDD} / \mathrm{Fs}$ and dioxin-like $\mathrm{PCB}$ from secondary copper and aluminum metallurgies in China. Chemosphere 75: 1173-1178. doi:10.1016/j.chemosphere.2009.02.052

Cains PW, McCausland LJ, Fernandes AR, Dyke P (1997) Polychlorinated dibenzo-p-dioxins and dibenzofurans formation in incineration: effects of fly ash and carbon source. Environ Sci Technol 31:776-785. doi:10.1021/es960468v

Chang M-B, Chung Y-T (1998) Dioxin contents in fly ashes of MSW incineration in Taiwan. Chemosphere 36:1959-1968. doi:10.1016/ S0045-6535(97)10080-7

Chi KH, Chang SH, Chang MB (2008) Reduction of dioxin-like compound emissions from a Waelz plant with adsorbent injection and a dual baghouse filter system. Environ Sci Technol 42:2111-2117

Chin YT, Lin C, Chang-Chien GP, Wang YM (2011) PCDD/Fs formation catalyzed by the copper chloride in the fly ash. J Environ Sci Heal A 46:465-470. doi:10.1080/10934529.2011.551725

Cobo M, Gálvez A, Conesa JA, Montes de Correa C (2009) Characterization of fly ash from a hazardous waste incinerator in Medellin, Colombia. J Hazard Mater 168:1223-1232. doi:10. 1016/j.jhazmat.2009.02.169

Conesa JA, Rey L, Egea S, Rey MD (2011) Pollutant Formation and emissions from cement kiln stack using a solid recovered fuel from municipal solid waste. Environ Sci Technol 45:5878-5884. doi:10. $1021 /$ es200448u

Dickson LC, Lenoir D, Hutzinger O (1992) Quantitative comparison of de novo and precursor formation of polychlorinated dibenzo-pdioxins under simulated municipal solid waste incinerator postcombustion conditions. Environ Sci Technol 26:1822-1828. doi:10.1021/es00033a017

Eiceman GA, Rghei HO (1982) Chlorination reactions of 1,2,3,4tetrachlorodibenzo-p-dioxin on fly ash with $\mathrm{HCl}$ in air. Chemosphere 11:833-839. doi:10.1016/0045-6535(82)90129-1

Fiedler H (2007) National PCDD/PCDF release inventories under the Stockholm Convention on Persistent Organic Pollutants. Chemosphere 67:S96-S108. doi:10.1016/j.chemosphere.2006.05.093

Fujimori T, Tanino Y, Takaoka M (2011) Role of zinc in MSW fly ash during formation of chlorinated aromatics. Environ Sci Technol 45: 7678-7684. doi:10.1021/es201810u

Fujimori T, Tanino Y, Takaoka M (2013) Coexistence of $\mathrm{Cu}, \mathrm{Fe}, \mathrm{Pb}$, and $\mathrm{Zn}$ oxides and chlorides as a determinant of chlorinated aromatics 
generation in municipal solid waste incinerator fly ash. Environ Sci Technol 48:85-92. doi:10.1021/es403585h

Gidarakos E, Petrantonaki M, Anastasiadou K, Schramm K-W (2009) Characterization and hazard evaluation of bottom ash produced from incinerated hospital waste. J Hazard Mater 172:935-942. doi: 10.1016/j.jhazmat.2009.07.080

Hagenmaier H, Brunner H, Haag R, Kraft M (1987a) Copper catalyzed dechlorination/hydrogenation of PCDD and PCDF and other chloroaromatic compounds. Environ Sci Technol 21:1085-1089

Hagenmaier H, Kraft M, Brunner H, Haag R (1987b) Catalytic effects of fly ash from waste incineration facilities on the formation and decomposition of PCDD and PCDF and other chloroaromatic compounds. Environ Sci Technol 21:1080-1984

Hajizadeh Y, Onwudili JA, Williams PT (2011) PCDD/F formation from oxy-PAH precursors in waste incinerator flyash. Chemosphere 85 : 1672-1681. doi:10.1016/j.chemosphere.2011.07.078

Hatanaka T, Imagawa T, Takeuchi M (2000) Formation of PCDD/Fs in artificial solid waste incineration in a laboratory-scale fluidized-bed reactor: influence of contents and forms of chlorine sources in hightemperature combustion. Environ Sci Technol 34:3920-3924. doi: $10.1021 / \mathrm{es} 991258 \mathrm{w}$

Hoffman RV, Eiceman GA, Long YT, Collins MC, Lu MQ (1990) Mechanism of chlorination of aromatic compounds adsorbed on the surface of fly ash from municipal incinerators. Environ Sci Technol 24:1635-1641. doi:10.1021/es00081a002

$\mathrm{Hu} \mathrm{J}$ et al (2013a) Occupational exposure to polychlorinated dibenzo-pdioxins and dibenzofurans, dioxin-like polychlorinated biphenyls, and polychlorinated naphthalenes in workplaces of secondary nonferrous metallurgical facilities in China. Environ Sci Technol 47: 7773-7779. doi:10.1021/es4016475

Hu J, Zheng M, Nie Z, Liu W, Liu G, Zhang B, Xiao K (2013b) Polychlorinated dibenzo-p-dioxin and dibenzofuran and polychlorinated biphenyl emissions from different smelting stages in secondary copper metallurgy. Chemosphere 90:89-94. doi:10. 1016/j.chemosphere.2012.08.003

Hung PC, Chen QH, Chang MB (2013) Pyrolysis of MWI fly ash — effect on dioxin-like congeners. Chemosphere 92:857-863. doi:10.1016/j. chemosphere.2013.04.042

Karasek F, Dickson L (1987) Model studies of polychlorinated dibenzop-dioxin formation during municipal refuse incineration. Science 237:754-756. doi:10.1126/science.3616606

Kawamoto K (2009) Potential formation of PCDD/Fs and related bromine-substituted compounds from heating processes for ashes. J Hazard Mater 168:641-648

Lasagni M, Collina E, Piccinelli E, Anzano MN, Piazzalunga A, Pitea D (2013) Kinetic modeling of the formation and destruction of polychlorinated dibenzo-p-dioxin and dibenzofuran from fly ash native carbon at $300{ }^{\circ} \mathrm{C}$. Environ Sci Technol. doi:10.1021/ es304902f

Lee C-C, Shih T-S, Chen H-L (2009) Distribution of air and serum $\mathrm{PCDD} / \mathrm{F}$ levels of electric arc furnaces and secondary aluminum and copper smelters. J Hazard Mater 172:1351-1356. doi:10.1016/ j.jhazmat.2009.07.148

Lenoir D, Klobasa O, Pandelova M, Henkelmann B, Schramm K-W (2012) Laboratory studies on formation and minimisation of polychlorinated dibenzodioxins and -furans $(\mathrm{PCDD} / \mathrm{F})$ in secondary aluminium process. Chemosphere 87:998-1002. doi:10.1016/j. chemosphere.2011.11.014

Liu GR et al (2009) Atmospheric emission of PCDD/Fs, PCBs, hexachlorobenzene, and pentachlorobenzene from the coking industry. Environ Sci Technol 43:9196-9201. doi:10.1021/Es902429m

Liu W, Zheng M, Liu W, Gao L, Su G, Zhang B (2011) Mechanism of polychlorinated diphenyl ether formation on a simulated fly ash surface. J Hazard Mater 186:814-819
Nie Z et al (2011) Estimation and characterization of PCDD/Fs, dl-PCBs, PCNs, $\mathrm{HxCBz}$ and $\mathrm{PeCBz}$ emissions from magnesium metallurgy facilities in China. Chemosphere 85:1707-1712

Nie Z, Liu G, Liu W, Zhang B, Zheng M (2012) Characterization and quantification of unintentional POP emissions from primary and secondary copper metallurgical processes in China. Atmos Environ 57:109-115

Rghei HO, Eiceman GA (1985a) Effect of matrix on heterogeneous phase chlorine substitution reactions for dibenzo-p-dioxin and $\mathrm{HCl}$ in air. Chemosphere 14:167-171. doi:10.1016/0045-6535(85)90095-5

Rghei HO, Eiceman GA (1985b) Reactions of 1,2,3,4-TCDD on fly ash in mixed gases of $\mathrm{H} 2 \mathrm{O}, \mathrm{NO} 2, \mathrm{HCl}$, and $\mathrm{SOX}$ in air. Chemosphere 14:259-265. doi:10.1016/0045-6535(85)90053-0

Riss A, Hagenmaier H, Weberruss U, Schlatter C, Wacker R (1990) Comparison of PCDD and PCDF levels in soil, grass, cow's milk, human blood and spruce needles in an area of PCDD/PCDF contamination through emissions from a metal reclamation plant. Chemosphere 21:1451-1456

Ryu J-Y, Kim D-H, Jang S-H (2013) Is chlorination one of the major pathways in the formation of polychlorinated naphthalenes (PCNs) in municipal solid waste combustion? Environ Sci Technol. doi:10. $1021 / \mathrm{es} 304735 \mathrm{n}$

Schwarz G, Stieglitz L (1992) Formation of organohalogen compounds in fly ash by metal-catalyzed oxidation of residual carbon. Chemosphere 25:277-282. doi:10.1016/00456535(92)90543-Z

Shih T-S et al (2008) Exposure and health-risk assessment of polychlorinated dibenzo-p-dioxins and dibenzofurans (PCDD/Fs) for sinter plant workers. Environ Int 34:102-107. doi:10.1016/j. envint.2007.07.010

Stieglitz L (1998) Selected topics on the de novo synthesis of PCDD/ PCDF on fly ash. Environ Eng Sci 15:5-18. doi:10.1089/ees.1998. 15.5

UNEP (2013) Toolkit for identification and quantification of releases of dioxins, furans and other unintentional POPs under Article 5 of the Stockholm Convention on Persistent Organic Pollutants

Weber P, Dinjus E, Stieglitz L (2001a) The role of copper(II) chloride in the formation of organic chlorine in fly ash. Chemosphere 42:579 582. doi:10.1016/S0045-6535(00)00230-7

Weber R, Ino F, Imagawa T, Takeuchi M, Sakurai T, Sadakata M (2001b) Formation of PCDF, PCDD, PCB, and PCN in de novo synthesis from PAH: Mechanisms and Correlation to Fluidized Bed Incinerators. Chemosphere 44:1429-1438

Weber R, Takasuga T, Nagai K, Shiraishi H, Sakurai T, Matuda T, Hiraoka M (2002) Dechlorination and destruction of PCDD, PCDF and PCB on selected fly ash from municipal waste incineration. Chemosphere 46:1255-1262. doi:10.1016/S0045-6535(01) 00268-5

Wielgosinski G, Grochowalski A, Holzer M, Cwiakalski W, Łechtanska P (2011) Dioxin emission from secondary copper smelter. Organohalogen Compd 73:79-82

Wikström E, Ryan S, Touati A, Telfer M, Tabor D, Gullett BK (2003) Importance of chlorine speciation on de novo formation of polychlorinated dibenzo-p-dioxins and polychlorinated dibenzofurans. Environ Sci Technol 37:1108-1113. doi:10. $1021 /$ es026262d

Yu B-W, Jin G-Z, Moon Y-H, Kim M-K, Kyoung J-D, Chang Y-S (2006) Emission of PCDD/Fs and dioxin-like PCBs from metallurgy industries in S. Korea. Chemosphere 62:494-501. doi:10.1016/j. chemosphere.2005.04.031

Zou C, Han J, Fu H (2012) Emissions of PCDD/Fs from steel and secondary nonferrous productions procedia. Environ Sci 16:279-288. doi:10.1016/j.proenv.2012.10.039 